\title{
Using Supervised Extensive Reading (SER) for Improving English as a Language of Instruction (LoI) and Learning: An Exploratory Study based on Observational Evidence
}

\author{
Jane Kembo
}

\begin{abstract}
Supervised Extensive Reading (SER) for 180 second language secondary school learners provided extra input in English.The learners read books graduated according to difficulty for two lessons a week.They made mandatory writtenreports on given forms and oral reports to their classmateson what they had read, as they gained confidence in self-expression. This went on for two years. Observationsshowed that there werelanguage in the areas of reading, grammar, writing and vocabulary improvementsand a spill-over into the performance of other subjects. While more studies are needed in the area, these observations show that SER holds promise for foreign and second language learners who use other languages as languages of instruction and learning and for whom the classroom is the main source of input in the target languages.
\end{abstract}

Index Terms - Extensive reading, input,reading reports, second language, acquisition, spillover.

\section{AIM OF THE PAPER}

The paperargues from observed evidence that Supervised Extensive Reading (SER)) can improve second language vicarious language acquisition as measured through reading, grammar, vocabulary and writing. In addition, there is a spill-over effect on other subjects because of improved second language proficiency.

\section{INTRODUCTION}

As a teacher, I noted that more than half my secondary students learning in English as Second Language (ESL) were struggling with grammar, reading comprehension, and writing in the language. In the first school, there was no intervention and the classes struggled with all subjects as well as the Language ofInstruction (LoI). As Bryant and Bradley observe, 'of all the things that children will do when they get to school reading and writing are the most basic, the most central and most critical. Practically, everything else that they do will be permeated by these skills. Hardly a lesson can be understood, hardly a project can be finished unless the children can read the books in front of them' (1985,p.1). Unfortunately, the skill that enables individual knowledge access, especially for self-directed learning is poorly developed in many learners.

In the school, as in many others, there was a very limited

Jane Kembo PhD, Rongo University, Box 103, 40404, RONGO, Kenya school library and most of the books there were subject specific texts for physics, chemistry, history and so on. We were also limited to reading comprehension passages in the English texts that had all other skills in them. Perhaps that was all the reading that many students did outside their subjects.

Aim of the project.

In a technical secondary school which did not take literature as one of the subjects of study, the aim of the project was to improve English language proficiency of learners of English as a Second Language ESL) through Supervised Extensive Reading (SER) as measured through grammar, vocabulary, and reading, spelling, and writing.The mini project was aimed at providing vicarious avenues for English language development and acquisition through Supervised Extensive Reading (SER) using materials that students would be able to relate to and that would be relevant to learners' daily lives and culture (Chio, 2009). Extensive reading, of graded pleasurable materials, namely story books, and use of activities that develop the skills of language learning: reading, writing, vocabulary and oral skills through writing guided book reports, oral reporting on their reading, vocabulary learnt, and spelling tests formed the core of the project. This project was carried out in four (4) secondary school classes that the researcher was teaching. Each class had 45 students.

Beginning of the project:

When I was posted to the second school, the head of the school appointed me library mistress and asked me to identify books for the school library with the help of colleagues in other departments and the English Department. In the languages department, the decision was made to buy story books. The reason was that stories hold an inherent characteristic to entertain, educate and provide input (Krashen,1987; Christy, Labby and Sullivan, 2016). Once we bought story books, we graded them according difficulty in terms of: ease of grammar, cultural experience, vocabulary and length, literary techniques used by authors (e.g. Chronology, flashbacks, plot, among others). This was to enable teachers help their students choose reading at each student's level of English language proficiency. The story books were both local and from other cultures and included detective novels that would appeal to the curiosity of teenagers. Somehow, through trial, we set up an Extensive Reading program for the whole school. As the school did not 
teach Literature, which was part of the English timetable,we had two free lessons each week in every class to devote to Extensive Reading.

\section{Background to the paper:}

In Kenya, as in other countries round the world, there is need to confirm that increase in access does not always translate into improvement in learning. There is need to confirm that teaching methods and learning materials need to be contextualized and for this to take place effective communication using a common language is vital. In many secondary schools, learners use the language of the area, and English, the Language of Instruction (LoI) is often met mostly in the classroom, in subjects taught in it and English and literature in English classes only. However, English is important both economically as the language for social mobility, and the language the dictates academic success. As Bryant and Bradley, state above, without adequate language facility, learners cannot access information in text books, neither can they understand examination instructions and questions. When they do, they will have not be able to adequately express what they understand.

The most geographically widely spoken language in the world which serves multiple purposes in a rapidly globalizing world is English language. Its mastery opens doors to more information than the mastery of any other language (Crystal, 2003).Thus, it is important for students in school whose LoI is English to acquire adequate proficiency in it.

Language proficiency and competence in language teaching, combined with the challenge students face when learning in a language unfamiliar to them, causes both teachers and students in LMIC serious communication and learning problems on a daily basis (UNESCO 2010). All language teaching emphasizes four basic skills: reading, listening, speaking and writing. The focal point of this study is reading as a skill that needs to be nurtured in all educational settings. But, further, the study was aimed at testing what began as an anecdotal observation, that ER can improve language skills: reading, speaking, writing, vocabulary and have a spillover effect into other subjects.

Since secondary school is terminal for most learners, it should provide certain basic abilities and skills that learners require both in their day to day civic and private lives.

English language is developing as the world's language of communication and medium of instruction at post-primary levels of education in most countries, Crystal quoted in a British Broadcasting Corporation radio program on "Will English Language Stay at the Top of the International Context" stated that out of over 6,000 languages, about 3,000 are endangered because of lack of use. He instead emphasized that "English language will remain the world's most spoken language because of globalization, citing that the fate of any language depends on the commitment of its users."

\section{Literature review:}

While Extensive Reading refers to the rather unregulated wide reading of material that is of interest to the learner, Supervised Extensive Reading (SER),is a similar concept, with the addition of teacher supervision. In other words, learners will still read what appeals to them from a given library, but the teacher of language will guide learners' choice of books to ensure maximum success and to reduce the circle of frustration from not understanding what is being read. A measure of success is critical in reading for the reader to go on to other books.

Story books have an inherent way of generating both curiosity and interest in the reader (Kembo, 1997), expanding vicarious experience and translocating readers to other cultures and lands in the imagination. In addition, stories embody language in actual use by characters in the stories, thus providing further input (Krashen, 1987) for language acquisition. Furthermore, the input reinforces rules andother aspects of grammar that have been taught in the language classes.

Other researches indicate that additional reading materials, appropriate to the reading level, that support the student's learning in and of English are also scarce both in the classrooms, wider community and the student's families (Negash 2006,). It has been suggested that learners who are only exposed to foreign language in class often learn greater grammatical knowledge at the expense of comprehension. As a response to the challenge, language education scholars (Canale and Swain, 1980; Howatt, 1984; Richards \& Rodgers, 2001; Scheckle, 2009;) suggest the adoption of divergent teaching approaches and this would include reading of other materials. However, these have been found difficult to implement in Second Language and Foreign Language contexts like Kenya and Rwanda, where learners and teachers' knowledge of the target language (TL) is limited. Fear of being judged limit learners' participation in English speaking contexts.

In studies done by Uwezo (2016) the reports decry the fact that rural school children were not acquiring literacy and numeracy as they should in Kenya and were performing well below expectation for their classes. Furthermore, it has been shown that 'that ninety percent of the teachers of English experienced problems in teaching reading and did not conduct library lessons at all due to lack of library resources" (Uwezo, 2016). In a similar study done with form four students in 1994, Kembo found that nearly $50 \%$ of 300 students tested in four inference categories (pronominal, textually explicit, textually implicit and pragmatic) were not able to make acceptable inferences in more than half the questions. Many students at university shy off analysis and evaluative questions because, unlike recall and comprehension questions, they depend on the learner's comprehension of the subject/topic as well as his ability to apply that knowledge and express it using the language of learning and find the best fit for the question task.

Learners should also posses' skills to breakdown the content of any subject using their proficiency levels in the four language skills, (Maleki and Zangani, 2007). Research suggests that one of the driving factors to quality education is for students to "better understand what is taught, analyze problems, express views, develop an enquiring mind and cultivate critical thinking" (Yip, 2003). Research hypothesizes (Komba et al., 2012 \& Feast 2002) that good mastery of the language skills leads to understanding content and hence contributes to good academic performance (Culliman, 2000). 
Limited language exposure and lack of reading materials, including text books (before 2018) made it difficult for learners to read outside class hours, thus exploiting an avenue that has been proved to be effective in Second Language (SL) acquisition and development (De Ath, 2001.)

The way to experience and acquire the language of school and the skills of reading and writing, therefore, need to be linked and strengthened through Supervised Extensive Reading, which is what the project will attempt to do.

\section{Methodology}

Books were graded according difficulty on the following criterial: length, difficulty of language, vocabulary and cultural familiarity. All the books used for the Supervised Extensive Reading (SER).

Every week each learner picked up a book with the help of the English language teacher and read it. At the end of their reading they individually filled in aone-page feedback form on the book. The ER protocol asked about the author, titles of the book, a summary of the story, what the reader had enjoyed in the story, the characters and so on. What character or characters they had liked and their reasons for the same. The exercise enabled learners to write what they had understood from their reading.

In addition, every reader was supposed to identify five new vocabulary item they had encountered in their reading and make a list and explain the meanings of the new words. After doing this, they were supposed to understanding of the new words by suing each of them in a sentence to demonstrate the same.

The weekly reports were to ensure that each learner was reading and could summarize what they had read in writing (Gordon and Braun, 1984). The aspect of putting it in writing was also thought to be helpful both to crystalize their own experiences and how they had reacted to their reading. It was thought that this would build their writing, and improve their use of any vocabulary they had learned in the reading.

In allowing learners to share their experiences with fellow classmates in oral presentations when they had read a particularly enjoyable book, learners were given opportunity to hone their listening as well as speaking skills.

\section{RESULTS}

In the months that followed my colleagues and I noticed that learners' language was improving. They were better able to express what they could remember from what they had read in the reports. The reports and the summary of the books became more focused, the language was more accessible and apt. The descriptions of the characters better focused showing that readers had become more sensitive to language use, character casting, description, actions and relationships within the books they were reading.

As the writing became better, we noticed after one year of the project that scores in grammar, precis, and spelling, and composition tests began to climb. The offshoot of the improvements in the language proficiency also seemed to affect the learners' understanding of tests in other subjects, and therefore, their performance in these other subjects, as reported by the teachers of the subjects. Thus, there seemed to be improved language across the curriculum. Whether the changes were significant was not tested, but it seems that there was anecdotal but strong observations by many teachers, to the effect that SER was influencing the general proficiency of learners in English as a Second Language (ESL) and LoI in the skills of: reading, writing, vocabulary, speaking and grammar.

\section{DISCUSSION}

The results agree with Input Hypothesis (Krashen, 1987) that comprehensible input and a little input that is above what the learners already know $(i+1)$ is good for SecondLanguage learners, as was noticed in the reporting on new vocabulary learned.

There is also ample evidence that reading in largely a result of vocabulary in the target language (Kembo, 1997; Devine, 1987; Benhardt and Kamil, 1995, Kembo, 2019).It is no wonder that the reading scores of the learners improved in the course of the project; this was able to be observed by other subject teachers, as there was spill over into the aptness of responses to exam questions.

That examination scores improved can be explained by the following reasons: the reading ability of the learners, in addition to their widening vocabulary as well writing skills. Writing and reading are called skills because they are sharpened through meaningful and consistent practice, which is what the SER afforded the learners. First, it gave each learner opportunity to use language in meaningful contexts to perform functions required by the project: summarizing, explaining vocabulary, expressing opinion about characters, making choices and supporting them when they argued about their likes and dislike of characters and the reasons for the same, and doing the same through oral presentations. Improvement in examination scores could also be attributed to the unconscious developmentof metacognitive skills related to text processing in general, and examinations question processing in particular, as learners became more sensitive to language and context (Barnett, 1989; Baker and Brown, 1984, Alderson and Lukmani, 1989, Baker, 2002)).In addition, better performance could also be attributed to the extended world view gained from the Extensive Reading program that provided wider schemata for mapping texts onto (An,2013) and thus spawning better test taking strategies (Amer, 1992) and better language proficiency for tackling exam questions ( Culliman, 2000).

The fact that each reader began reading at his own language ability also built their confidence both as readers and learners, thus breaking what has been called the vicious cycle of frustration. The cycle consists of readers, especially second or foreign language learners, not learning to read effectively because, by the time they have struggled through paragraphs, they have forgotten the content because of a mainly bottom up processing of textual information(Graesser, 1981; Berman, 1984;Cataldo and Oakhill, 2000).

There is adequate evidence that there is a strong reading-writing connection. The vocabulary that learners acquire influences how well they write. Although both take practice, the language of the writer influences both process 
and product. (Gordon, and Braun, 1983). It is, therefore, no wonder that teachers of other subjects, as well as the teachers of English, began to notice that compositions and assignments were better focused and that examination answers were better expressed (Christy, Labby, and. Sullivan, 2016)., as opposed to the reports that are common in national examination reports that 'learners do not seem to understand questions, and when they do, they seem to lack the language with which to express their understanding'(KNEC, 1990, 2015, 2017).

\section{CONCLUSIONS AND RECOMMENDATIONS:}

The following conclusions can be made from this mini project:

First, that SER works in providing input for the Target languages, especially where the classroom is the only source of LoI. Two, for it to work well, it needs to be structured and consistent. Three, the reading books need not only be interesting, but must also be graded so that each learner begins and climbs through the gradings at his own pace. This lessens reader frustration of not understanding what they are reading. Four, the teachers oversighting SER must do more to make the projects work: looking at reports, isolating what is interesting and helping learners make oral reports. The teachers must also be voracious readers themselves, as this is the only way they will be able to grade and help learners choose appropriate books for themselves. Four, the observations made with respect to spill over show that SER works especially where there is limited input in Foreign and Second language situations. It provides supplementary source of input.

Otherteachers and researchersshould try this out in quasi -experimental studies to modify or find models of this that work better. This is especially urgent in the telephony era, where very little reading and extended writing happens now except in school, and learners seem to be losing the skills instead of developing them. Besides, I notice that most undergraduate Second Language speakers can get away with colloquial language in conversation in English, but can hardly write three fluent paragraphs in the language of instruction (LoI). Ways of improving languages of learning must be developed for the majority of learners who cannot access school content effectively for current or future needs.

\section{REFERENCES}

[1] Alderson, J.C. and Lukmani, Y. (1989). Cognition in Reading: Cognitive Levels Embodied in Test Questions. Reading in a Foreign Language, 5(2) 253-270.

[2] Amer, A.A.(1992). Teaching EFL students to use text-taking strategy. Language Testing, 10, 967-979.

[3] An.S. (2013). Schema theory in Reading. In Theory and Practice in Language Studies. 3(1) 130-134.

[4] Baker, L. (2002). Metacognition in Comprehension Instruction. In Block, C.C. and Pressley, M. (Eds.). Comprehension Instruction: Research-based Best Practices. New York, NY: Guildford Press.

[5] Baker, L. and Brown, A.(1984). Metacognition Skills and Reading. InPearson, D.P. (Ed.) Handbook of Reading Research. New York, Longman.

[6] Barnett, M.A. (1989). More than Meets the Eye: Foreign Language Reading. Prentice Hall; NJ: Englewood Cliffs.

[7] Benhardt, E. B. and Kamil, M.L.(1995). Interpreting Relationships Between L1 and L2 Reading: Consolidating the Linguistic Threshold and Linguistic Interdependence Hypothesis. Applied Linguistics. 16(1), 15-21.
[8] Berman, R. (1984).Syntactic Components of the Foreign Language Reading Process.in Alderson and Urquhart (Eds). Reading in a Foreign Language. 139-156.London: Longman.

[9] Bryant, P. and Bradley, L. (1985). Children's Reading Problems. Psychology of Education. p.1. Basil Blackwell.

[10] Cain , K. Oakhill, J. and Barnes, M.A. and Bryant, P.E (2000). Comprehension Skill, Inference-making Ability and their relation to Knowledge. Memory and Cognition, 29(6) 850-859.

[11] Canale,M.and Swain, (1980). From communicative competence to communicative language pedagogy. In Richards, J. C., \& Schmidt, R. W. (Eds.), Language and Communication, pp. 2-27. London: Longman.

[12] Cataldo, M.G. and Oakhill, J.(2000). Are Poor Comprehenders Inefficient Searchers? An Investigation into the Effects of Text Representation and Spatial Memory on the Ability to Locate Information in Text. Journal of Education Psychology, 92(4). 791801.

[13] Chio, Kut U. ( (2009). Reading and Second Language Acquisition.HKBU.Papers in Applied Language Studies. 13,153-174.

[14] Christy, W., Labby, S., and. Sullivan, S.L (2016). The impact of pleasure reading on academic success. The Journal of Multidisciplinary Graduate Studies.

[15] Creel, S (2015). The impact of assigned reading on reading pleasure in young adults. Journal of Research of Libraries and Young Adults, 5 -6. Retrieved http://www.yalsa.ala.org/jrlya/2015/02/the-impact-of-assigned reading-on- reading-pleasure-in-young-adults/

[16] Crystal,D. (2003). India opts for English language teaching. BBC News Online 10 October 2008. Available online at http://news.bbc.co.uk/2/hi/africa/7663298.stmPolitzer, M. 2008.

[17] Culliman, B. (2000). Independent reading and school achievement Research Journal of the American Association of School Librarians, 3, 1-24. Retrieved from http://www.yalsa.ala.org/aasl/sites/ala.org.aasl/filess/content/aaslpubs andjournals/slr/ vol13/SMLR_independent reading_V3.pdf.

[18] Daily Nation, November, 21, 2017,

[19] De Ath, P.(2001). The NUie literacy experiment. In W. B. Alley (Guest Ed.|), Book-based Approaches to Raising Literacy in developing Countries. International Journal of Educational Research, 35 137-146.

[20] Devine, J. (1987). General Language Competence and Adult Second Language Reading. In Devine, J and Carrell, P.L. and Eskey, D.E.(Eds.).Research in Reading in English as a Second Language. TESOL, Washington,D.C.

[21] Fraenkel, J.R., \& Wallen, N.E., (2008). How to Design and Evaluate Research in Education.

[22] Gahigi, M. (2008). Rwanda: English Language Teaching Kicks Off. Retrieved from http://allafrica.com/stories/200812010940.html

[23] Gall, M.D., Borg, W.R. \& Gall, J.P. (2003). Educational Research: An Introduction (7th Ed). New York: Longman, Inc.

[24] Gordon, C.J. and Braun, C. (1983). Using Story Schema as an AID to Reading and Writing. The Reading Teacher, 34, 261-268.

[25] Graesser, A. C. (1981). Prose Comprehension Beyond the Word. New York, Springer- Verlag.

[26] Howatt, (1984) Communicative Competence: An Experiment in Foreign-Language Teaching. Philadelphia: The Centre for Curriculum Development, Inc.http://www.ibe.unesco.org

[27] Kembo, J. (1997). Inferencing in a second language: how far is Language Proficiency a factor? Unpublished $\mathrm{PhD}$ Thesis, University of Reading, UK.

[28] Kembo, J. (2019). Towards a Hierarchy of Inferences: Are some Inferences more challenging for Second Language readers? International Journal of Education and Psychological Research (IJEPR), 8(1), 1-6

[29] KNEC: Kenya National Examination Report (1990) Kenya. Government Printers.

[30] KNEC: Kenya National Examination Report (2015) Kenya. Government Printers,

[31] KNEC: Kenya National Examination Report (2017) Kenya. Government Printers

[32] Komba et al., (2012). Factors Related to Performance in Reading English Language. Unpublished M.Ed. Thesis. University of Nairobi.

[33] Krashen, S.D. (1987). Principles and Practice in Second Language Acquisition. Prentice-Hall

[34] Maleki and Zangani, (2007). Noel C. Bacchus, Guyana Farewell: A Recollection of Childhood in a Faraway Place.

[35] NegashNigissie(2006), English language in Africa: An impediment or a contributor to development? 
[36] Obondo, M. A. (1996). From Trilinguals to Bilinguals? A study of the social and linguistic consequences of language shift on a group of urban Luo children in Kenya. Doctoral dissertation. Centre for research on Bilingualism. Stockholm University.

[37] Ouane, A. and Glanz, C. (2010). Why and How Africa Should Invest in African Languages and Multilingual Education. Hamburg: UNESCO Institute for Lifelong Learning.

[38] Richards, J.and T. Rodgers.(2001). Approaches and Methods in Language Teaching (2nd edn.).Cambridge: Cambridge University Press.

[39] Scheckle, (2009) Andrewes and IllesLanguage, 68, 1 (1992)

[40] Krauss, M. (2019). The world's Languages in Crisis, University of Alaska, Fairbanks. UN Report (2019).

[41] UNESCO (2006) Education for All Global Monitoring Report 2006: Literacy for life World Data On Education 2006). World Data on Education.

[42] UNESCO

https://www.teachingenglish.org.uk/article/Promoting-Learner-Autono my- Through-Communication-Strategy-Training.

[43] Uwezo (2016): Are Our Children Learning?Uwezo Kenya Sixth Learning Assessment Report. Nairobi: Twaweza, East Africa.

[44] Uwambayinema, (2015) Implementation of the English medium policy in Rwandan primary schools: A case of Nyarugenge district, Rwanda.

[45] Weir, C.(1993). Developing and Understanding Language Tests. Prentice Hall, UK.

[46] Yip, (2003).Interlanguage in Schools. Edward Arnold Press. 